\title{
TUNING THE ELECTRONIC, PHOTOPHYSICAL AND CHARGE TRANSFER PROPERTIES OF SMALL D-A MOLECULES BASED ON THIENOPYRAZINE-TERTHIENYLS BY CHANGING THE DONOR FRAGMENT: A DFT STUDY
}

\author{
YOUSSEF AIT AICHA I,3, SI MOHAMED BOUZZINE 2,3, TOURIYA ZAIR', MOHAMMED BOUACHRINE4, \\ MOHAMED HAMIDI', GUILLERMO SALGADO-MORAN ${ }^{5}$, R. RAMIREZ TAGLE', \\ LUIS H. MENDOZA-HUIZAR ${ }^{7}$ *

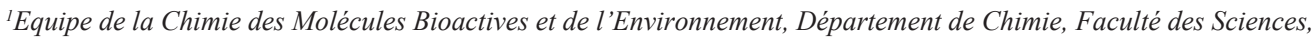 \\ Université Moulay Ismail, BP11201 Zitoune, Meknès, Morocco \\ ${ }^{2}$ Centre Régional des Métiers d'Education et de Formation, BP 8, Errachidia, Morocco. \\ ${ }^{3}$ Equipe d'Electrochimie et Environnement, Faculté des Sciences et Techniques, Université Moulay Ismaïl, B.P. 509 Boutalamine, Errachidia, Morocco. \\ ${ }^{4}$ E.S.T.M, Université Moulay Ismail, Meknès, Morocco \\ ${ }^{5}$ Departamento de Ciencias, Químicas Facultad de Ciencias Exactas, Universidad Andres Bello, Sede Concepción, Chile. \\ ${ }^{6}$ Universidad Bernardo O'Higgins. Facultad de Ingeniería, Ciencia y Tecnología. Av. Viel 1497, Santiago, Chile. \\ ${ }^{7}$ Universidad Autónoma del Estado de Hidalgo. Academic Area of Chemistry. Carr. Pachuca-Tulancingo Km. 4.5 Mineral de la Reforma, Hgo, México.
}

\section{ABSTRACT}

Four acceptor-donor organic conjugated molecules based on thieno[3,4-b]pyrazine-terthienyls were analyzed in order to explore the effect of the donor substituent on their molecular structures, electronic and optical properties. Density Functional Theory (DFT) and Time-Dependent Density Functional Theory (TD/DFT) calculations were carried out employing the B3LYP hybrid functional in combination with the 6-31G(d,p) basis set. The results suggests that the addition of electron-donating substituents to the conjugated molecules can diminish their energy gap value, which is beneficial to the photon harvesting. The lowest-lying absorption spectra of compounds substituted with electron donor groups exhibited a red-shift and a high oscillation factor compared with the unsubstituted molecule. Additionally, the ionization potential $(I P)$, electron affinity $(E A)$, reorganization energy $(\lambda)$ and open-circuit voltage $\left(V_{\text {oc }}\right)$ of the molecules were evaluated. According to these values, the molecules show good photovoltaic properties, and efficient charge transfer for hole and electron and balanced charges.

Keywords: Thienopyrazine; charge transfer properties; donor-acceptor; DFT.

\section{INTRODUCTION}

During the past few years, the development of new narrow band gap $\pi$-conjugated polymers has attracted a great interest. These materials can be used in the fabrication of efficient organic light emitting devices (OLED), organic photovoltaic cells (OPC) and organic field-effect transistors (OFET) ${ }^{1-}$ 3 Thus, it is not so strange that many researchers have devoted significant efforts to develop methods and procedures oriented to control the band gap values of these conjugated materials. A common strategy to design low band gap polymers is the synthesis of polymers by alternating electron-rich (donor) and electron-deficient units (acceptor). Thus, these polymers can be used to build internal donor-acceptor (D-A) structures along a polymer backbone. .-9 $^{4-9}$ However, the design of polymers with small optical gaps remains as a challenge; because these materials have to lead to efficient exciton dissociation and simultaneously maintain large open-circuit voltages together with large short-circuit currents. ${ }^{6-9}$

D-A $\pi$-conjugated materials exhibit small optical band gaps, which are useful in the fabrication of OPC devices. Nevertheless, recently there is an increased interest in the synthesis of new small D-A molecules, due to their advantages such as high purity, definition and well-ordered molecular structure, and intrinsic monodispersity. Among these D-A small molecules, the family of thieno[3,4-b]pyrazines can be used as excellent precursors for the production of low band gap conjugated oligomers/polymers. ${ }^{10-13}$ Thus, a detailed investigation at the molecular level would allow us to analyze the influence of electron-donor substitution on the physicochemical properties of thieno[3,4-b]pyrazines based on terthienyl system. In this sense, the Density Functional Theory (DFT) has been applied successfully to study the electronic properties of $\pi$-conjugated polymers to evaluate their optical band gaps. ${ }^{10-}$ ${ }_{13}$ Therefore, in this work, we present a theoretical DFT study of four D-A conjugated compounds based on thienopyrazine-terthienyls (TPRi, $i=1-4$ ), see Figure 1. The ground and charged states of all the oligomers are analyzed using the B3LYP functional, and the low-lying excited state will be examined using TD-DFT with the 6-31G(d,p) basis set. In addition, the energies of the highest occupied molecular orbital (HOMO) and the lowest unoccupied molecular orbital (LUMO) levels, band gap energy, charge-carrier transport, absorption wavelengths and emission wavelengths of studied molecules are evaluated in this work. In addition, we explore the effects of the electron-donor substituent on the electronic and photophysical properties of the resulting D-A molecules. We consider that all this fundamental information is valuable in designing and making promising materials for the building of optoelectronic devices.

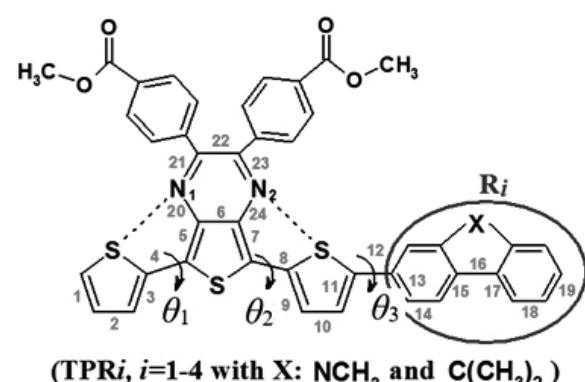

(TPRi, $i=1-4$ with $\mathrm{X}: \mathrm{NCH}_{3}$ and $\mathrm{C}\left(\mathrm{CH}_{3}\right)_{2}$ )

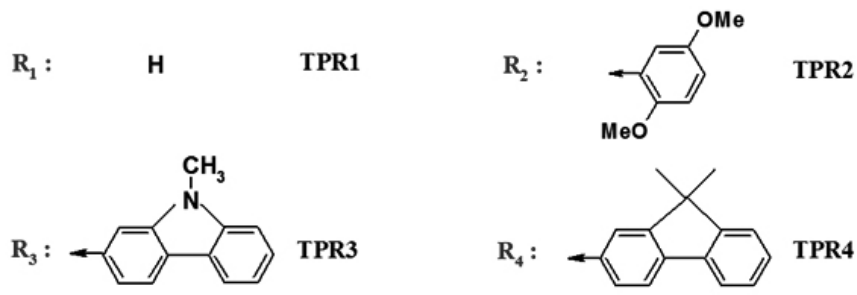

Figure 1. Chemical structure and parameters geometrical (di, $\theta \mathrm{i})$ of study oligomers.

\section{METHODS}

2.1. Theoretical background

The intermolecular transport of charge carriers can be seen as a charge hopping process. This process can be described as an electron or hole transfer 
from a charged molecule to an adjacent neutral molecule, which can be represented by a self-exchange reaction as follows:

$$
\mathrm{M}^{ \pm}+\mathrm{M}^{*} \rightarrow \mathrm{M}+\mathrm{M}^{* \pm}
$$

where $\mathrm{M}^{ \pm}$denotes the molecule in the cationic and anionic states and $\mathrm{M}^{*}$ is the neighboring molecule in the neutral state. The calculation of the electronic hopping rate $K_{C T}$ for this self-exchange reaction is given by equation (2), according to the semi-classical Marcus theory, ${ }^{14,15}$ which has been previously used. ${ }^{16,17}$

$$
K_{C T}=\frac{4 \pi^{2}}{h} \frac{1}{\sqrt{4 \pi \lambda \mathrm{k}_{\mathrm{B}} T}} t^{2} \exp \left[-\frac{\lambda}{4 \mathrm{k}_{\mathrm{B}} T}\right]
$$

$k_{\mathrm{B}}$ and $T$ are the Boltzmann constant and temperature, respectively, $\lambda$ is the reorganization energy and is the electronic coupling term between two adjacent molecules, often called charge transfer integral. As seen in equation (2), there are two factors $\lambda$ and $t$ determining the $K_{C T}$ value. However, the intermolecular charge transfer range in no crystal is rather narrow and value is very limited. Therefore $K_{C T}$ of charges are expected to be dominated by $\lambda$ in the exponential term of equation (2). ${ }^{18,19}$ On the other hand, $\lambda$ could be the most important factor that governs the short-circuit current density. According to the previous equation, for an efficient charge transfer between neighboring molecules, $\lambda$ should be small and can be approximated by:

$$
\lambda^{ \pm}=\left[E^{ \pm}\left(\mathrm{M}^{0}\right)-E^{ \pm}\left(\mathrm{M}^{ \pm}\right)\right]+\left[E^{0}\left(\mathrm{M}^{ \pm}\right)-E^{0}\left(\mathrm{M}^{0}\right)\right]
$$

where $E^{ \pm}\left(\mathrm{M}^{ \pm}\right), E^{0}\left(\mathrm{M}^{0}\right), E^{ \pm}\left(\mathrm{M}^{0}\right)$ and $E^{0}\left(\mathrm{M}^{ \pm}\right)$represent the total energies of the cationic (anionic) species in the optimized geometry, the total energy of the neutral molecule in the optimized geometry, the total energy of the cation (or anion) in neutral geometry and the total energy of the neutral molecule in cationic (or anionic) geometry, respectively, see Figure 2.

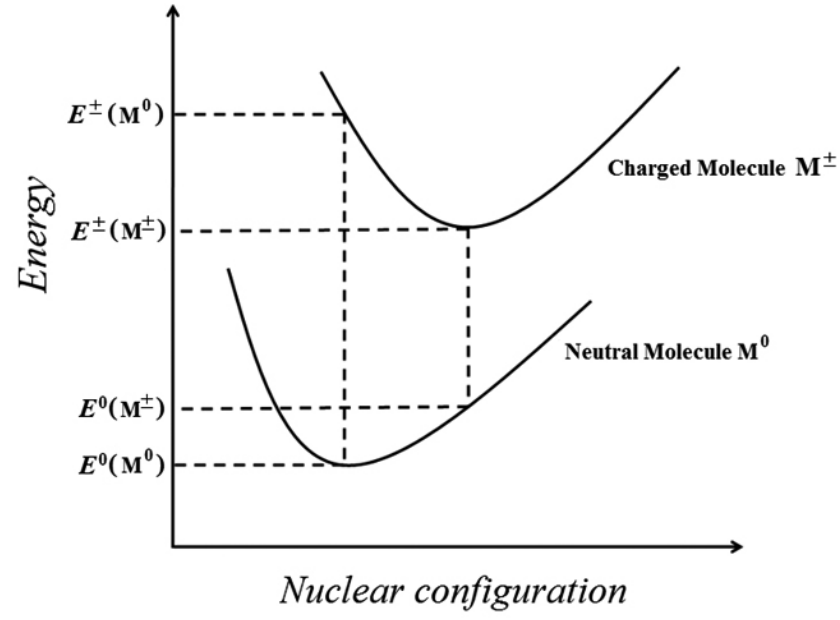

Figure 2. Schematic plot of reorganization energy.

Electron affinity $(E A)$ and ionization potential $(I P)$ are the most importan properties to calculate the charge injection barriers. The values of the parameters $I P$ and $E A$, both vertical and adiabatic are calculated by using the following expressions:

$$
\begin{aligned}
& I P_{\mathrm{a}}=E^{+}\left(\mathrm{M}^{+}\right)-E^{0}\left(\mathrm{M}^{0}\right) \text { and } I P_{\mathrm{v}}=E^{+}\left(\mathrm{M}^{0}\right)-E^{0}\left(\mathrm{M}^{0}\right) \\
& E A_{\mathrm{a}}=E^{0}\left(\mathrm{M}^{0}\right)-E^{-}\left(\mathrm{M}^{-}\right) \text {and } E A_{\mathrm{v}}=E^{0}\left(\mathrm{M}^{0}\right)-E^{-}\left(\mathrm{M}^{0}\right)
\end{aligned}
$$

in these equations the subscript " $a$ " indicate adiabatic while that the subscript " $v$ " means vertical. Thus, $I P$ a is the adiabatic ionization potential and $I P$ is the vertical one. Similarly, $E A$ is the electron affinity evaluated adiabatically while $E A_{v}$ is the evaluated vertically. On the other hand, the extraction potential for electron $(E E P)$ and hole $(H E P)$ for the studied compounds are calculated by using the equation (6):

$$
H E P=E^{+}\left(\mathrm{M}^{+}\right)-E^{0}\left(\mathrm{M}^{+}\right) \text {and } E E P=E^{0}\left(\mathrm{M}^{-}\right)-E^{-}\left(\mathrm{M}^{-}\right)
$$

Comparing the reorganization energies with the short circuit current density, it can be evaluated as:

$$
J_{s c}=\int_{\lambda} \operatorname{LHE}(\lambda) \emptyset_{\text {injection }} \eta_{\text {collection }} d \lambda
$$

where $J_{S C}$ value depends on the charge collection efficiency and the electron injection efficiency $\left(\emptyset_{\text {injection }}\right)$ which is related to the $\Delta G^{\text {injection }}$ Moreover, it is possible to evaluate the light harvesting efficiency $(L H E)$, which is directly linked $J_{S C}$ with and has to be as high as possible to maximize the photo current response. $L H E$ can be expressed as: ${ }^{20,21}$

$$
\text { LHE }=1-10^{-f}
$$

where $f$ is the oscillator strength of the oligomers associated to the maximum absorption of charge transfer interaction. Also, it is important to consider that the sunlight-to-electricity conversion efficiency $(P C E)$, is evaluated through the open-circuit photo voltage $\left(V_{O C}\right), J_{S C}$ and the fill factor $(F F)$ as compared to the incident solar power $\left(P_{\text {in }}\right)$. The $P C E$ can be written as:

$$
P C E=\frac{F F \times J_{\mathrm{sc}}}{P_{\mathrm{in}}} \times V_{\mathrm{oc}}
$$

Therefore, from equation (9), the high values of indicate the potential of having a large PCE value in the OPC. The open circuit voltage of the bulk heterojunction solar cell is related to the difference between the HOMO of the electron donor and the LUMO of PCBM of the electron acceptor. Therefore the values have been calculated from the following expression: ${ }^{22}$

$$
V_{\text {oc }}=\left|E_{\text {HOMO }}^{\text {Donor }}\right|-\left|E_{\text {LUMO }}^{\text {Acceptor }}\right|-0.3
$$

\subsection{Computational methods}

All the calculations were performed with the Gaussian 09 package. ${ }^{23}$ The density functional theory (DFT) with Becke's three-parameter functional and Lee-Yang-Parr functional (B3LYP), ${ }^{21-26}$ and the $6-31 \mathrm{G}(\mathrm{d}, \mathrm{p})$ basis set were employed to investigate the optimization of structures in the gas phase, without any symmetry constrains. The excitation energies and oscillator strengths of the oligomers were obtained by TD-DFT, in the gas phase, in conjunction with a polarizable continuum model (PCM) ${ }^{27-28}$ to evaluate the effect of the solvent (Chloroform). In addition, various properties of these compounds, such as ionization potentials, electron affinities, hole extraction potential, electron extraction potential and reorganization energy $(\lambda)$, were derived from B3LYP/6-31G(d,p) single point calculations

\section{RESULTS AND DISCUSSION}

\subsection{Ground state geometries}

Probably, the major obstacle to the understanding of fundamental properties of conducting polymers is the lack of enough detailed structural data. In order to determine the geometrical parameters (bond lengths $(d \mathrm{i})$ and dihedral angles $\left.\left(\theta_{\mathrm{i}}\right)\right)$, the molecules were fully optimized in their ground states at the B3LYP/6$31 \mathrm{G}(\mathrm{d}, \mathrm{p})$ level of theory. ${ }^{29}$ All these parameters are summarized in Table S1 of the supporting information. The bond lengths and inter-cyclic bond angles do not suffer significant variation with the change of substituent in the oligomers As shown in Table S1 (see the Supporting Information), the inter-ring bond lengths $(d \mathrm{i})$ are in an average of $1.437 \AA$ for $d 1,1.434 \AA$ for $d 8$, and $1.463 \AA$ for $d 12$. The B3LYP optimized structures of TPRi, $\mathrm{i}=1-4$ are presented in Figure 3. The results of the optimized structures revealed that the molecules have almost planar conformations, ${ }^{10,30,31}$ and the terthienyl backbones adopt a predominately S-trans configuration analogous to $\alpha$-terthiophene. ${ }^{32}$ The dihedral angles $\left(\theta_{1}, \theta_{2}\right)$ between thiophene rings and the thieno[3,4-b]pyrazine ring were $\left(176^{\circ}, 176^{\circ}\right)$ for both TPR 1 and $\mathrm{TPR}_{2},\left(177^{\circ}, 173^{\circ}\right)$ for both $\mathrm{TPR}_{3}$ and $\mathrm{TPR}_{4}$, while the dihedral angle $\theta_{3}$ is anti-left side with a value close to $168^{\circ}$ for $\mathrm{TPR}_{2}$ and $157^{\circ}$ for both $\mathrm{TPR}_{3}$ and $\mathrm{TPR}_{4}$. Examination of the non-bonded distances between sulfur and nitrogen (see Figure 3 ) shows that these distances $(3.05 \AA)$ are significantly shorter than the sum of the van der Waals radii of sulfur and nitrogen $(3.35 \AA)$. 


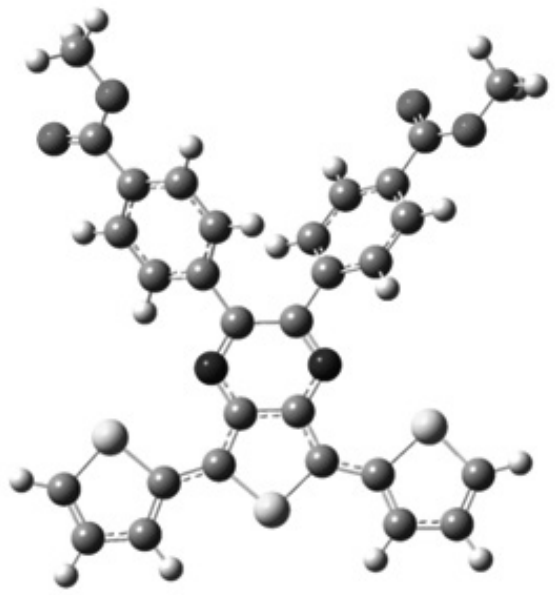

$\mathbf{T P R}_{1}$

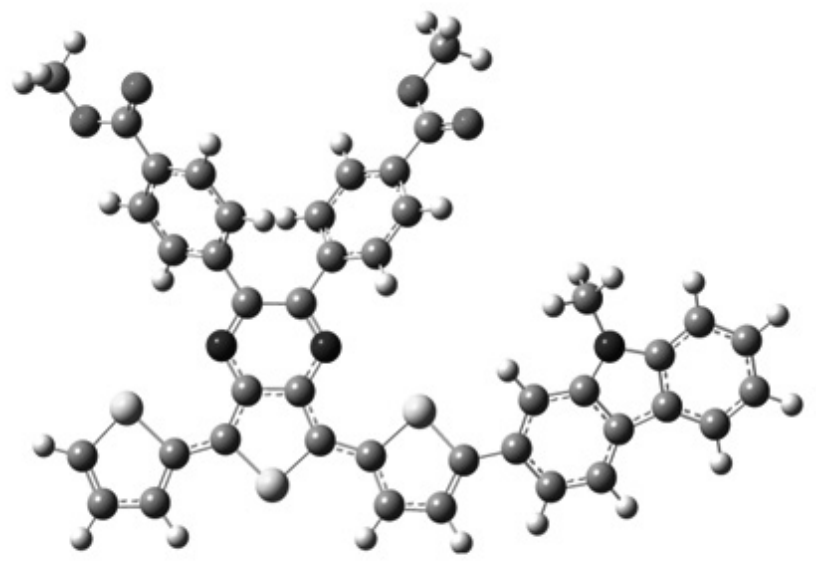

$\mathbf{T P R}_{3}$

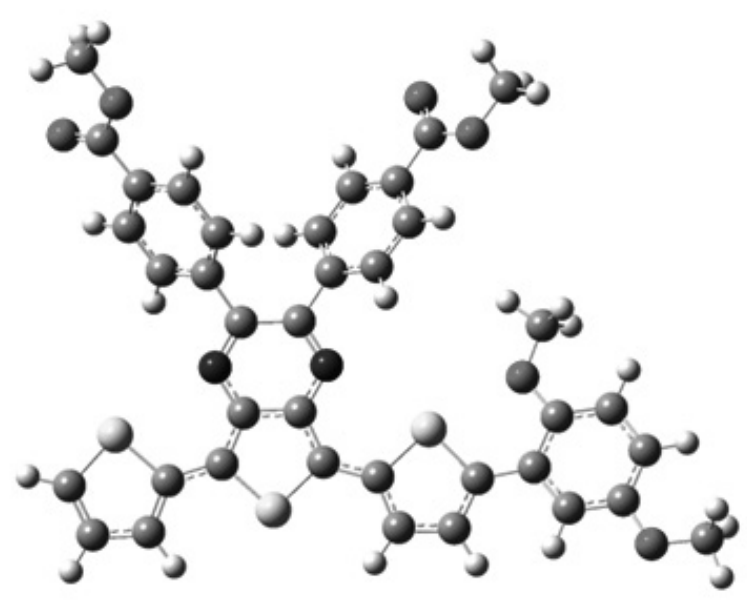

$\mathbf{T P R}_{2}$

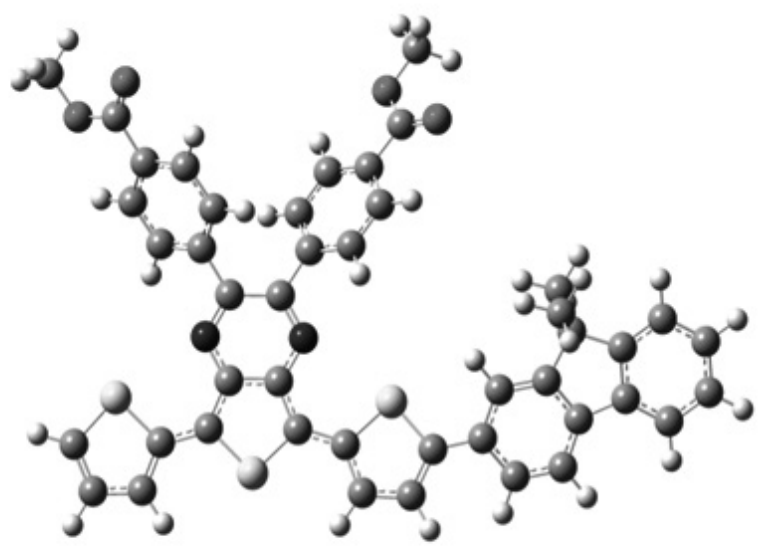

$\mathbf{T P R}_{4}$

Figure 3. Optimized Molecular structures obtained by B3LYP/6-31G(d,p) of the studied molecules.

\subsection{Doped structures}

The cationic and anionic geometries of TPRi, $\mathrm{i}=1-4$ were optimized at the B3LYP/6-31G(d,p) level of theory and the bond lengths and dihedral angles are compiled in Table S2 (see the Supporting Information). If one compares the values reported in Tables $\mathrm{S} 1$ and $\mathrm{S} 2$, it is possible to note that the dihedral angles $\theta_{\mathrm{i}}, \mathrm{i}=1-3$ of each molecule in cationic and anionic states is increasing and they are tending to be more planar than their corresponding neutral ground states. Also, note that the distance $d_{\mathrm{S}-\mathrm{N}}$ between the sulfur and nitrogen atoms is shortened. Last results suggest that the oxidation or reduction of these molecules improved their planarity and forced the attractive interactions between sulfur and nitrogen atoms. To elucidate the difference in geometries between neutral and doped states, we present in Figure 4 the variation of the bond length values of the oligomer in their neutral and ionic forms labeled with the number of bond.

In the last figure, note that the distances $d \mathrm{i}, \mathrm{i}=1-11$ of the simple bonds become shorter and the double ones become longer. This variation is clearly observed in thiophene ring fused with pyrazine ring ( $d \mathrm{i}, \mathrm{i}=4-8)$ and in thiophene ring substituted with donor moiety $(d \mathrm{i}, \mathrm{i}=9-11)$. On the other hand the distances $d \mathrm{i}, \mathrm{i}=12-19$ of the donor units and the distances $d \mathrm{i}, \mathrm{i}=20-24$ of the pyrazine ring are not affected appreciably. Thus, the optimized geometry of the cationic compound indicates the formation of the positive polaron defect localized in the middle of (thiophene-thienopyrazine-thiophene) units. A quinoid-like distortion emerges as result of the oxidation. These results are summarized in Figure 5(A). In the anionic state of TPRi, the bond lengths values $d \mathrm{i}, \mathrm{i}=1$ 19 of each oligomer are changed slightly compared with their corresponding in neutral states, however the bond lengths $d \mathrm{i}, \mathrm{i}=20-24$ in pyrazine ring are affected as mentioned in Table 1.

Table 1. Bond lengths values for $d \mathrm{i}, \mathrm{i}=20-24$ of TPRi in the ground and anionic states and their Ecart.

\begin{tabular}{|c|c|c|c|c|c|}
\hline$D \mathrm{i}$ & $d_{20}$ & $d_{21}$ & $d_{22}$ & $d_{23}$ & $d_{24}$ \\
\hline $\mathrm{TPRi}$ & 1.358 & 1.318 & 1.467 & 1.319 & 1.356 \\
\hline TPRi- & 1.350 & 1.346 & 1.432 & 1.350 & 1.345 \\
\hline Ecart & -0.008 & +0.028 & -0.035 & +0.031 & -0.011 \\
\hline
\end{tabular}

Indeed, the radical anion charge formed by reduction of TPRi is localized on pyrazine ring. Figure 5(B) shows the structure of studied molecules in their anionic forms. This structure is consistent with the reported by Kenning et al. for 2,3-dimethylthieno[3,4-b]pyrazine. ${ }^{33}$ 

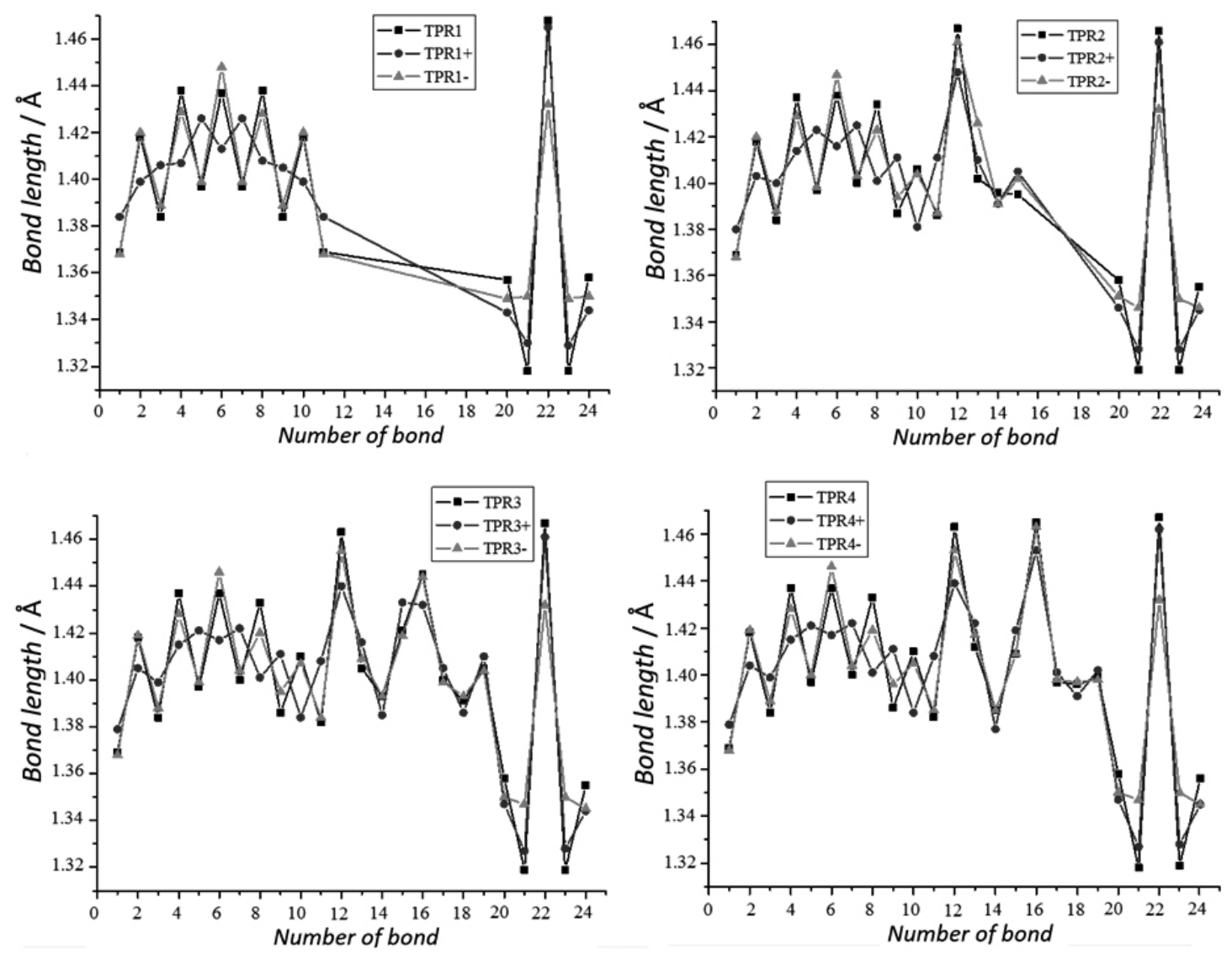

Figure 4. Variation of the bond lengths values of TPRi $\mathrm{i}=1-4$, in neutral and doped states with the number of bonds.
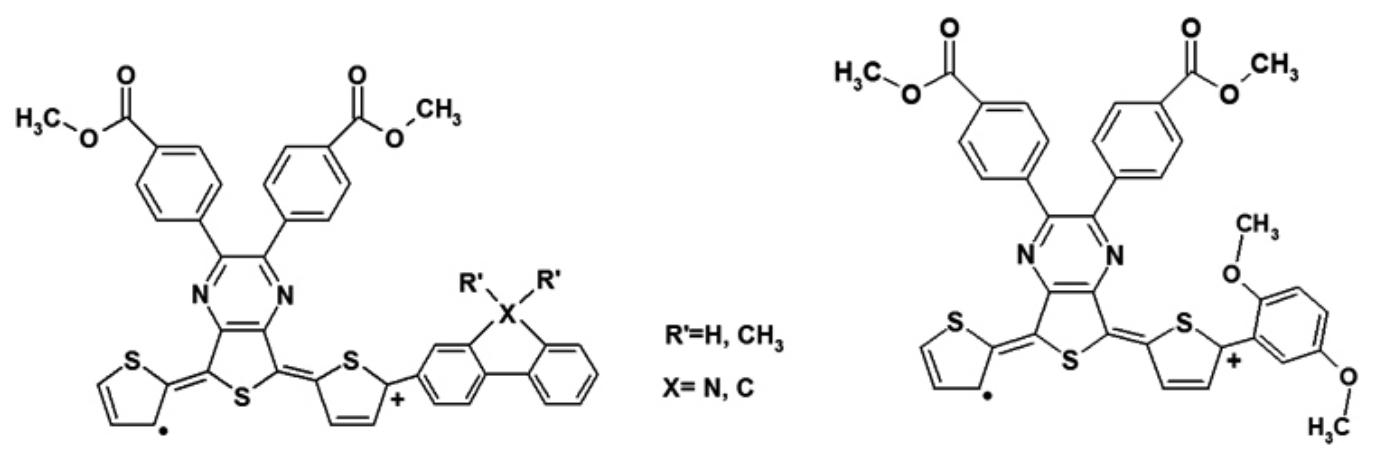

(A)

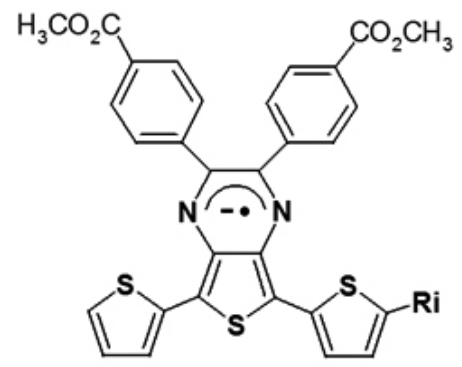

(B)

Figure 5. Proposed structures for (A) radical cations and (B) radical anions 
4.3. HOMO, LUMO and gap energies

Table 2 reports the values of the electronic parameters (HOMO, LUMO and band gap) calculated at the B3LYP/6-31G(d,p) level of theory for the conjugated molecules in their ground and ionic states.

Table 2. The $E_{\text {номо }}, E_{\text {LUмо }}$ and $E_{\mathrm{g}}(\mathrm{eV})$ energies of the studied compounds in ground, cationic and anionic states obtained at the $\mathrm{B} 3 \mathrm{LYP} / 6-31 \mathrm{G}(\mathrm{d}, \mathrm{p})$ level of theory.

\begin{tabular}{|c|c|c|c|c|c|c|c|c|c|c|c|c|}
\hline \multicolumn{4}{|c|}{ Neutral form } & \multicolumn{4}{|c|}{ Cationic form } & \multicolumn{4}{|c|}{ Anionic form } & \\
\hline TPRi & $\mathrm{TPR}_{1}$ & $\mathrm{TPR}_{2}$ & $\mathrm{TPR}_{3}$ & $\mathrm{TPR}_{4}$ & $\mathrm{TPR}_{1}$ & $\mathrm{TPR}_{2}$ & $\mathrm{TPR}_{3}$ & $\mathrm{TPR}_{4}$ & $\mathrm{TPR}_{1}$ & $\mathrm{TPR}_{2}$ & $\mathrm{TPR}_{3}$ & $\mathrm{TPR}_{4}$ \\
\hline$E_{\text {номо }}$ & -5.05 & -4.75 & -4.83 & -4.85 & -8.56 & -7.78 & -7.64 & -7.66 & -0.68 & -0.76 & -0.91 & -0.92 \\
\hline$E_{\text {LUMO }}$ & -2.77 & -2.68 & -2.77 & -2.78 & -6.30 & -5.79 & -5.74 & -5.75 & 0.68 & 0.58 & 0.48 & 0.49 \\
\hline \multirow[t]{2}{*}{$E_{\mathrm{g}}$} & $2.27 \mathrm{a}$ & 2.06 & 2.05 & $2.06 \mathrm{~b}$ & 2.26 & 1.99 & 1.90 & 1.91 & 1.36 & 1.34 & 1.39 & 1.41 \\
\hline & $\begin{array}{c}E_{\mathrm{g}}=2.47 \\
\text { ref. } 37\end{array}$ & & & $\begin{array}{c}E_{\mathrm{g}}=2.16 \\
\text { ref } 38 .\end{array}$ & & & & & & & & \\
\hline
\end{tabular}

It is important to indicate that phenyl substituents on the pyrazine of dithienylthienopyrazine system obviously participate in the conjugated structure and red shift the absorption maximum. ${ }^{34}$ This fact has as consequence the lowest $E$ evaluated for TPR1 $(E=2.275 \mathrm{eV})$ in comparison with the gaps for thieno[3,4-b]pyrazine analogues $\left(E_{\mathrm{g}}=2.75 \mathrm{eV}\right),{ }^{10}$ and 5,7-dithien-2ylthieno[3,4-b]pyrazine $\left(E_{\mathrm{g}}=2.38 \mathrm{eV}\right),{ }^{35-36}$ obtained at the B3LYP/6-311G(d,p) and B3LYP/6-31G(d,p) levels of theory respectively; and the experimentally reported for heterocyclic-thiophene-conjugated polymers with electron donoracceptor fragment $\left(E_{\mathrm{g}}=2.47 \mathrm{eV}\right) \cdot{ }^{37}$ The band gap value calculated for TPR4 ( $E_{\mathrm{g}}$ $=2.069 \mathrm{eV})$ is in agreement with previous theoretical reports $(E=2.16 \mathrm{eV}){ }^{38}$ Also, note from Table 2, that the substitution of $\alpha$-hydrogen in the thiophene ring in TPR 1 by different electron-rich donor groups (p-dimethoxyphenyle, carbazole and fluorene), is causing that $E$ in the neutral state decreases about $0.2 \mathrm{eV}$ and the values of the HOMO and LUMO are being modified. The HOMO energy values of compounds TPRi, $\mathrm{i}=2-4$ increases compared with the unsubstitued compound TPR1. However, the LUMO's value of the compounds analyzed practically were not modified, but a significant deviation is observed for the LUMO's value of the compound substituted with the p-dimethoxyphenyle group $\left(\mathrm{TPR}_{2}\right)$. Also, it is well known that the electron donor groups elevate the energy value of both HOMO and LUMO levels. ${ }^{39}$ This result indicates that the reduction of $E$ is due principally to the HOMO's destabilization. Thus, the alternation of the donor and acceptor units leads to the band gap reduction. When we pass from the neutral to ionic states, the electronic properties are modified appreciably (see Table 2), especially in the case of the anionic state because its energy gap is decreasing about $0.7 \mathrm{eV}$ compared with $0.1 \mathrm{eV}$ in the cationic state. In both cases, the doping process causes that the molecules TPRi to be more conductor in its ionic state. These results indicate a diminishing of the flexibility of the structure assuring a more planar geometry.

\subsection{Frontier molecular orbital}

It is useful to examine the HOMO and LUMO's values of these oligomers and polymers because the relative ordering of the occupied and virtual orbitals provides a reasonable qualitative indication of the excitation properties and of the ability of electron or hole transport. ${ }^{40}$ In Figure 6 are reported the contour plots of HOMO and LUMO of TPRi, i=1-4, obtained at the B3LYP/6$31 \mathrm{G}(\mathrm{d}, \mathrm{p})$ level of theory. As shown all frontier orbitals in the oligomers of all series under study spread over the whole $\pi$-conjugated backbone. In general, the HOMO possesses an antibonding character between the subunits. This situation may explain the nonplanarity observed for these oligomers in their ground states. On the other hand, the LUMO of all the oligomers generally shows a bonding character between the subunits. This implies that the singletexcited state involving mainly the promotion of an electron from the HOMO to the LUMO should be more planar.

\subsection{Photovoltaic parameters}

It is well accepted that the architecture of photoactive layer is one of the principle factors that increases the solar cell efficiency. Nowadays, bulk heterojunction (BHJ) structure based on blends of conjugated polymers as electron donors and soluble fullerene derivatives (PCBM) as electron acceptors represent one of the most efficient type of organic photovoltaic devices. ${ }^{41-44}$ Here, it is analyzed the photovoltaic properties of the compounds TPRi as donor blended with one derivative of PCBM among three derivatives (C60, C61 and $\mathrm{C} 70$ ), in order to establish a suitable choice for high photovoltaic performance. Alignment of the energy levels in OPV is of great importance to achieve high and an efficient charge transport from the donor polymer to the acceptor fullerene. In Figure 7, a schematic view of the energy levels of each donor oligomer TPRi and acceptor fullerene derivative in a bulk heterojunction is shown.

For each PCBM derivatives, the difference $\Delta E_{\text {LUMO }}$ between the LUMO energy levels of (TPRi, $\mathrm{i}=1-4)$ and their corresponding theoretical values of are reported in Table S3 (see Supporting information), A graphical comparison of the $\Delta E_{\text {LUMO }}$ and has been drawn in Figure 8 to represent the results more clearly. 
номо

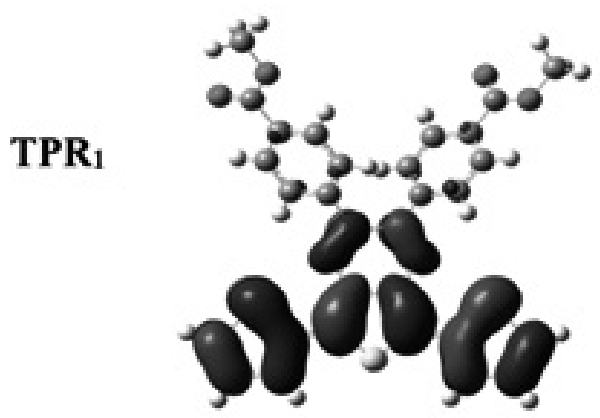

TPR=

\section{LUMO}
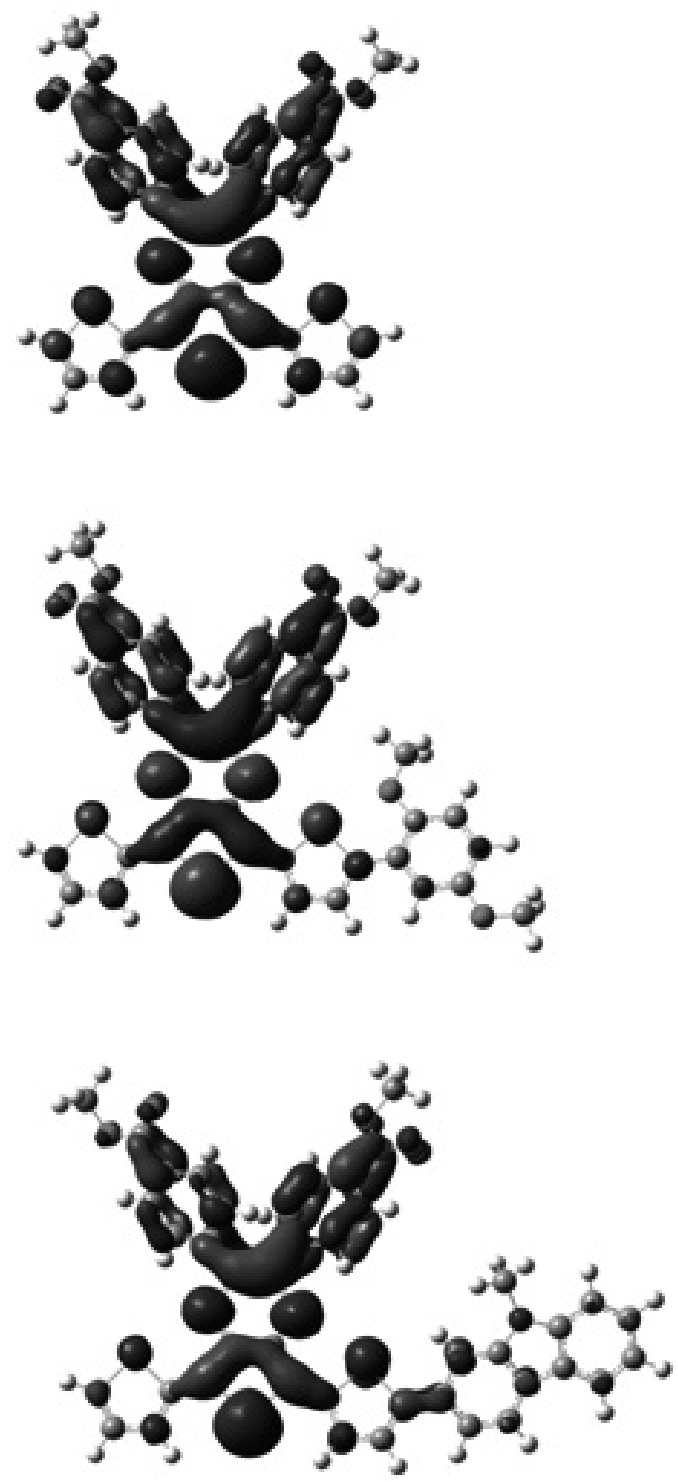

Figure 6. The electron density plots of the HOMO and LUMO of studied molecules. 


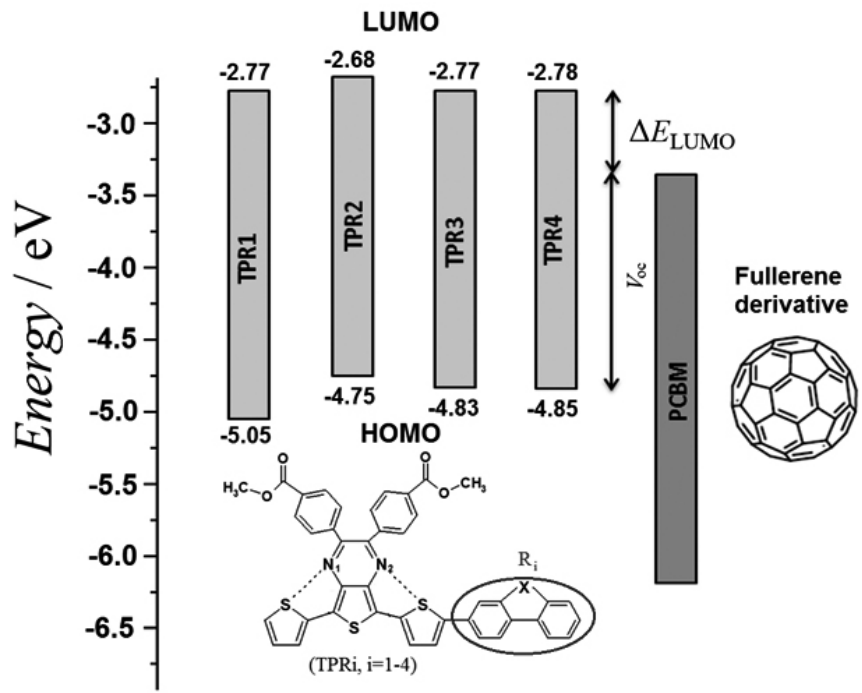

Figure 7. Energy scheme for TPRi/PCBM

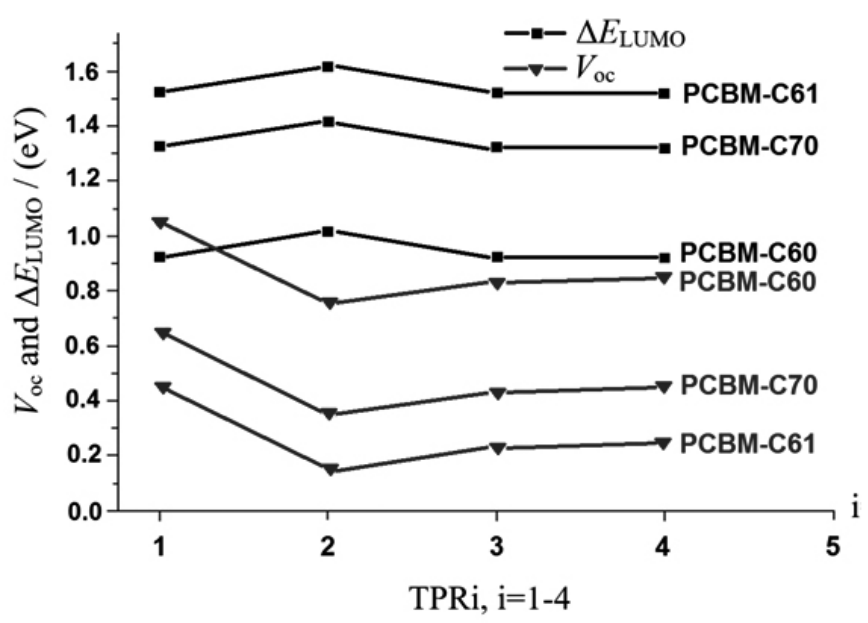

Figure 8. Graphical representation of $\Delta E_{\text {aum }}$ and calculated at the B3LYP/6-31G(d,p) level of theory for each TPRi and PCBM.

As shown in Figure 8, and $\Delta E_{\text {umo }}$ parameters values depend on the kind of acceptor used in cell due to the difference in energy level LUMO of acceptor. In general, a minimum energy difference of $\sim 0.3 \mathrm{eV}$ between the LUMO energy levels of the donor polymer and the acceptor is required to guarantee an efficient charge separation at the interface of donor materials and PCBM. From Figure 8 and Table S3, it is clear that the acceptor that satisfies these exigencies is the PCBM-C60. In this case, the open circuit potential range is 0.752 to $1.050 \mathrm{eV}$, while the $\Delta E_{\mathrm{LuO}}$ is varying between $0.924-1.015 \mathrm{eV}$. These values suggest that the PCBM-C60 can allow a high and favorable TPRi/PCBM-C60 interface for an efficient charge transfer instead others interfaces such as either TPRi/PCBM-C61 or TPRi/PCBM-C70.

Scharber and coworkers ${ }^{22}$ have proposed a relationship between $P C E$ of the PCBM-based on BHJ solar cell and the electronic structure of the constituent donor polymer such as $E$ and the $E_{\text {umo }}$ level (and in turn the $E_{\text {HOmo }}$ ), as shown partially in Figure 9. We used these values in the Scharber's diagram to estimate the $P C E$ of the BHJ solar cells made of these molecules. The diagram indicates that all TPRi oligomers exhibit similar power conversion efficiency close to $2 \%$.

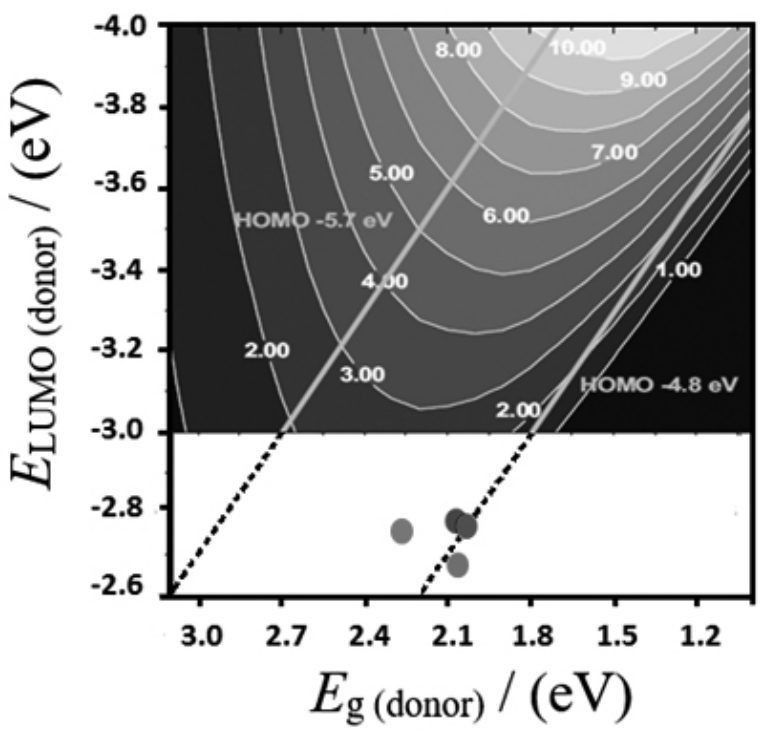

Figure 9. Scharber's diagram to estimate $P C E(\%)$ of the BHJ solar cells made of TPRi and PCBM-C60.

4.6. Transport and transfer charge properties

In organic semiconductor materials to increase the injection ability for hole and electron lower $I P$ and higher $E A$ is decisive to maintain a good performance..$^{45-47}$ In this section, it is reported the $I P$ and $E A$ values calculated at the B3LYP/6-3 l $/ \mathrm{G}(\mathrm{d}, \mathrm{p})$ level of theory, for both vertical and adiabatic approximations, and the extraction potentials $H E P$ and EEP for the hole and electron, respectively. Table 3 reports these values for all studied TPRi calculated using the equations (4)-(6).

Table 3. Ionization potentials $(I P)$, electron affinities $(E A)$, extraction potentials (HEP and EEP) and reorganization energies $(\lambda)$ for each Molecule [all in $\mathrm{eV}]$.

\begin{tabular}{|l|c|c|c|c|c|c|c|c|}
\hline $\mathrm{TPRi}$ & $I P_{\mathrm{a}}$ & $I P_{\mathrm{v}}$ & $H E P$ & $A E_{\mathrm{a}}$ & $A E_{\mathrm{v}}$ & $E E P$ & $\lambda^{+}$ & $\lambda^{-}$ \\
\hline $\mathrm{TPR}_{1}$ & 6.127 & 6.271 & 5.985 & 1.722 & 1.599 & 1.843 & 0.286 & $0, .244$ \\
\hline $\mathrm{TPR}_{2}$ & 5.690 & 5.832 & 5.549 & 1.721 & 1.602 & 1.838 & 0.283 & 0.236 \\
\hline $\mathrm{TPR}_{3}$ & 5.707 & 5.854 & 5.575 & 1.845 & 1.716 & 1.954 & 0.279 & 0.238 \\
\hline $\mathrm{TPR}_{4}$ & 5.729 & 5.871 & 5.594 & 1.845 & 1.722 & 1.956 & 0.277 & 0.234 \\
\hline
\end{tabular}

From Table 3 it is clear that both adiabatic and vertical $(I P / I P)$ of substituted compounds TPRi, i=2-4 are $(5.690 / 5.832 \mathrm{eV}),(5.707 / 5,854 \mathrm{v}$ eV) and $(5.729 / 5,871 \mathrm{eV})$ respectively, which are smaller than that those obtained for the parent molecules TPR $(6.127 / 6.271 \mathrm{eV})$. On the other hand, the vertical $E A_{\mathrm{v}}$ values of TPRi, i=1-4 increase in the order of $\mathrm{TPR}_{1}<\mathrm{TPR}_{2}<\mathrm{TPR}_{3}<\mathrm{TPR}_{4}$, which is the same order for the adiabatic $E A$ values with small deviation for TPR1. This result indicates that the ionization potentials become lower and the electronic affinities become higher after substituent by p-dimethoxyphenyle, carbazole and fluorene groups. The changing trends of the IPS and EAs for all oligomers are similar respectively to those evaluated in the case of the extraction potentials for hole $H E P$ and electron EEP (see Table 3 ). Thus, it is concluded that by substitution, the hole and electron-injection abilities are improved in donor-acceptor oligomer TPRi.

On the other hand, $\lambda$ is one of the dominant factors that influence on the charge-carrier transport rate, according to equation (3). Another factor is the charge-transfer integral $V$, which is not generally considered, because it is very small in solid film materials. ${ }^{18}$ Table 3 reports the $\lambda^{+}$and $\lambda^{-}$values calculated through equation (3). As emitting layer materials, it is necessary to achieve the balance between hole injection and electron acceptance through lower $\lambda$ values and a bigger charge-transport rate. As shown in this table, there is a little difference of $\lambda^{+}$and $\lambda^{-}$among TPR and the others compounds. This indicates that when the $\alpha$-hydrogen in the thiophene ring TPR is replaced by different substituent, the reorganization energies, $\lambda^{+}$and $\lambda$; are decreased 
about $0.01 \mathrm{eV}$ suggesting that there is a slightly improvement in charge carries transport for substituted compounds TPRi, $\mathrm{i}=2-4$. Moreover, all oligomers have nearly a same reorganization energy values for hole and electron transport (the difference among them is the order of $0.04 \mathrm{eV}$ ), implying that they may be good ambipolar materials. The calculated $\lambda^{+}$of TPR 1 is 0.286 $\mathrm{eV}$ at the B3LYP/6-31G(d,p) level of theory, which is similar to the value of 2,3-diphenylthieno[3,4-b]pyrazine calculated at B3LYP/6-311G(d,p) level by $\mathrm{G}$. Saranya et al $(0.29 \mathrm{eV}),{ }^{44}$ whereas the $\lambda$ - for TPR1 is $0.244 \mathrm{eV}$ lesser than that of 2,3-diphenylthieno[3,4-b]pyrazine $(0.27 \mathrm{eV}) \cdot{ }^{48}$ Hence, connecting the thiophene rings to the thieno[3,4-b]pyrazine core revealed that the new designed compound formed (TPR $)$ might be efficient as an electron transporter and as a hole transporter.

\subsection{Absorption spectra}

As illustrated in Table 4, we found the values of the vertical excitation energy $E_{\text {ex }} \lambda_{\text {max }}$ absorption, the oscillator strength (O.S) and the molecular orbital (MO/character) along with the main excitation configuration of all the compounds. These values are calculated in chloroform and in the gas phase through the TD/DFT method starting with the optimized geometry obtained at the B3LYP/6-31G(d,p) level of theory.

Table 4. Electronic transition data obtained by the TD/B3LYP calculation for all studied compounds

\begin{tabular}{|c|c|c|c|c|c|c|}
\hline TPRi & Transition & $\begin{array}{c}\lambda_{\mathrm{ab}}(\mathrm{nm}) \\
\mathrm{HCCl}_{3}\end{array}$ & $\begin{array}{c}\lambda_{\mathrm{ab}}(\mathrm{nm}) \\
\mathrm{Gas}\end{array}$ & $E_{\mathrm{ex}}(\mathrm{eV})$ & Os & $\mathrm{MO} /$ Characters \\
\hline $\mathbf{T P R}_{1}$ & $\begin{array}{l}\mathrm{S}_{0} \rightarrow \mathrm{S}_{1} \\
\mathrm{~S}_{0} \rightarrow \mathrm{S}_{2} \\
\mathrm{~S}_{0} \rightarrow \mathrm{S}_{3}\end{array}$ & $\begin{array}{l}655.6 \\
444.7 \\
395.9\end{array}$ & $\begin{array}{l}631.1 \\
438.4 \\
394.9\end{array}$ & $\begin{array}{l}1.964 \\
2.827 \\
3.139\end{array}$ & $\begin{array}{l}0.149 \\
0.047 \\
0.001\end{array}$ & $\begin{array}{c}\mathrm{H} \rightarrow \mathrm{L}(0.69) \\
\mathrm{H}-1 \rightarrow \mathrm{L}(-0.23), \mathrm{H} \rightarrow \mathrm{L}+1(0.66) \\
\mathrm{H}-5 \rightarrow \mathrm{L}(0.55), \mathrm{H}-4 \rightarrow \mathrm{L}(-0.40)\end{array}$ \\
\hline $\mathrm{TPR}_{2}$ & $\begin{array}{l}\mathrm{S}_{0} \rightarrow \mathrm{S}_{1} \\
\mathrm{~S}_{0} \rightarrow \mathrm{S}_{2} \\
\mathrm{~S}_{0} \rightarrow \mathrm{S}_{3}\end{array}$ & $\begin{array}{l}728.6 \\
493.9 \\
482.8\end{array}$ & $\begin{array}{l}701.6 \\
488.9 \\
478.4\end{array}$ & $\begin{array}{l}1.767 \\
2.536 \\
2.591\end{array}$ & $\begin{array}{l}0.277 \\
0.001 \\
0.099\end{array}$ & $\begin{array}{c}\mathrm{H} \rightarrow \mathrm{L}(0.70), \mathrm{H} \rightarrow \mathrm{L}+2(-0.11) \\
\mathrm{H}-1 \rightarrow \mathrm{L}(-0.44), \mathrm{H} \rightarrow \mathrm{L}(0.53) \\
\mathrm{H}-1 \rightarrow \mathrm{L}(0.54), \mathrm{H} \rightarrow \mathrm{L}+2(0.44)\end{array}$ \\
\hline $\mathbf{T P R}_{3}$ & $\begin{array}{l}\mathrm{S}_{0} \rightarrow \mathrm{S}_{1} \\
\mathrm{~S}_{0} \rightarrow \mathrm{S}_{2} \\
\mathrm{~S}_{0} \rightarrow \mathrm{S}_{3}\end{array}$ & $\begin{array}{l}721.9 \\
525.0 \\
473.8\end{array}$ & $\begin{array}{l}697.6 \\
514.6 \\
473.1\end{array}$ & $\begin{array}{l}1.777 \\
2.409 \\
2.620\end{array}$ & $\begin{array}{l}0.354 \\
0.001 \\
0.010\end{array}$ & $\begin{aligned} & \mathrm{H} \rightarrow \mathrm{L}(0.70) \\
& \mathrm{H}-1 \rightarrow \mathrm{L}(0.70) \\
& \mathrm{H}-3 \rightarrow \mathrm{L}(-0.13), \mathrm{H}-2 \rightarrow \mathrm{L}(-0.46) ; \mathrm{H} \rightarrow \mathrm{L}+1(0.51)\end{aligned}$ \\
\hline $\mathbf{T P R}_{4}$ & $\begin{array}{l}\mathrm{S}_{0} \rightarrow \mathrm{S}_{1} \\
\mathrm{~S}_{0} \rightarrow \mathrm{S}_{2} \\
\mathrm{~S}_{0} \rightarrow \mathrm{S}_{3}\end{array}$ & $\begin{array}{l}719.6 \\
473.0 \\
467.7\end{array}$ & $\begin{array}{l}692.2 \\
469.6 \\
458.9\end{array}$ & $\begin{array}{l}1.791 \\
2.640 \\
2.701\end{array}$ & $\begin{array}{l}0.360 \\
0.014 \\
0.202\end{array}$ & $\begin{array}{c}\mathrm{H} \rightarrow \mathrm{L}(0.70) \\
\mathrm{H}-2 \rightarrow \mathrm{L}(-0.13), \mathrm{H}-1 \rightarrow \mathrm{L}(-0.44) ; \mathrm{H} \rightarrow \mathrm{L}+1(0.52) \\
\mathrm{H}-1 \rightarrow \mathrm{L}(0.52), \mathrm{H} \rightarrow \mathrm{L}+1(0.45)\end{array}$ \\
\hline
\end{tabular}

From Table 4, note that the lowest lying singlet excited states for all the title compounds comprise mainly an electronic transition between the HOMO and LUMO. Also, observe that all compounds exhibit a strong absorption band in the visible region around 631-701 nm, which favors the photon harvesting. ${ }^{49}$ For parent molecule TPR1, the strongest absorption is located at $635 \mathrm{~nm}$. This value is in agreement with the reported for a similar compound $(552 \mathrm{~nm}) \cdot{ }^{34}$ Note that typical conjugated solubilizing groups such as ester groups (situated on phenyl rings of TPR1) contribute to light harvesting and charge transport. ${ }^{50}$ Important bathochromic shifts can be noticed upon going from TPR1 to substituted compounds TPR2-TPR4 with a red shift high than $60 \mathrm{~nm}$. This bathochromic effect is due to the increasing of conjugation bond lengths attributed to the substitution by donor electron groups. Similar effects are detected on the oscillator strength. The simulated absorption spectra of the studied compounds obtained at TD/B3LYP/6-31G(d,p) level is shown in Figure 10. The spectra show that the compounds TPRi, $\mathrm{i}=1-3$ present two bands; one at lower energies from 631 to $702 \mathrm{~nm}$ with main intensity; the second one located at higher energies varying from 438 to $478 \mathrm{~nm}$, while the compound TPR4 have just one intense band at low energy situated at $696 \mathrm{~nm}$. This indicates that the compounds TPRi, $\mathrm{i}=1-3$ have a major absorption range (absorb at blue and red shifts) than compound TPR4 (absorb only at red shifts).

Furthermore, the difference between wavelengths computed in chloroform and in the gas phase are no more than $27 \mathrm{~nm}$, suggesting that the effect of solvent on the absorption spectra is negligible; which is in agreement with the experimental results for 2,3-disubstitued thieno[3,4-b]pyrazine [51-52].

\subsection{Emission spectra}

In order to study the emission photoluminescence properties of TPRi the adiabatic emission spectra were calculated using the optimized geometry of the first excited singlet state at the TD-DFT/B3LYP/6-31G(d,p) level in the gas phase. The calculated emission data are shown in Table 5. As in the case of the absorption spectra, the emission peaks with the large oscillator strength of the compounds are all assigned to $\pi \rightarrow \pi^{*}$ character arising from $\mathrm{S}_{1}$, a $\mathrm{HOMO} \rightarrow$ LUMO transition. When analyzing the transition configuration of the fluorescence, we noted that the calculated fluorescence is the reverse process of the lowest lying absorption. The values calculated of the fluorescence wavelength in the gas phase for TPRi, $\mathrm{i}=1-4$ are located at 831.8, 908.6, 904.1, and $895.3 \mathrm{~nm}$, respectively. All molecules upon study show a greater stokes shift more than $200 \mathrm{~nm}$. It may be explained because of these compounds have a higher degree of planarity in their excited state than ground state which as described above when examining frontier molecular orbitals, HOMO and LUMO. $^{53}$

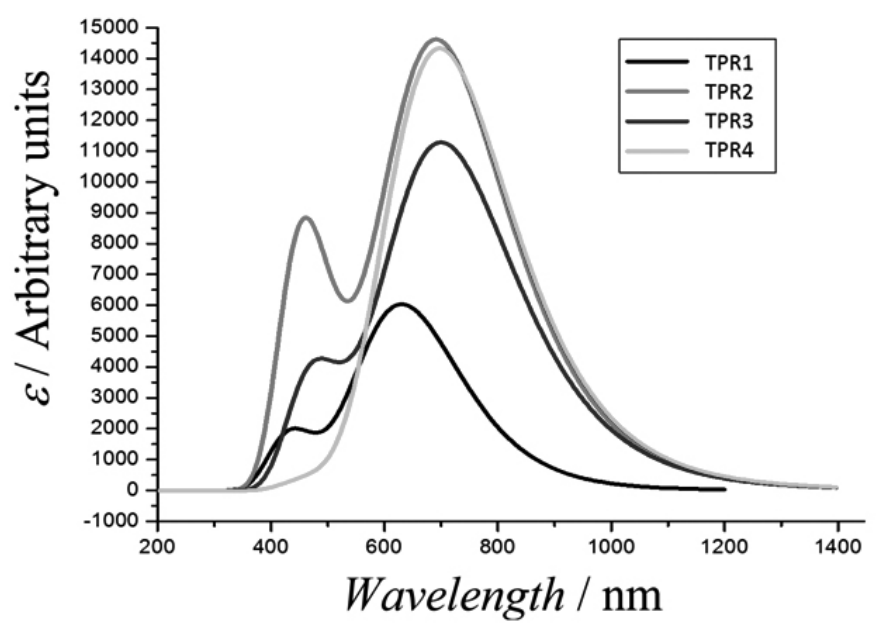

Figure 10. Simulated absorption spectra of the TPRi molecules in the gas phase. 
Table 5. Emission spectra data for all molecules obtained with TD-DFT/B3LYP/6-31G(d,p).

\begin{tabular}{|c|c|c|c|c|c|}
\hline TPRi & $\lambda_{\text {em }}(\mathrm{nm})$ & $E_{\mathrm{ex}}(\mathrm{eV})$ & Os & SS & MO/Characters \\
\hline \multirow{3}{*}{ TPR1 } & 831.8 & 1.490 & 0.104 & & $\mathrm{H} \rightarrow \mathrm{L}(0.69), \mathrm{H} \rightarrow \mathrm{L}+2(0.11), \mathrm{H} \leftarrow \mathrm{L}(-0.11)$ \\
& 496.0 & 2.499 & 0.061 & 200.7 & $\mathrm{H}-1 \rightarrow \mathrm{L}(-0.20), \mathrm{H} \rightarrow \mathrm{L}+1(0.67)$ \\
& 424.1 & 2.923 & 0.402 & & $\mathrm{H}-1 \rightarrow \mathrm{L}(0.66), \mathrm{H} \rightarrow \mathrm{L}+1(0.19)$ \\
\hline & 908.6 & 1.365 & 0.198 & & $\mathrm{H} \rightarrow \mathrm{L}(0.70), \mathrm{H} \rightarrow \mathrm{L}+2(-0.11), \mathrm{H} \leftarrow \mathrm{L}(-0.11)$ \\
TPR2 & 543.6 & 2.281 & 0.029 & 207.0 & $\mathrm{H}-1 \rightarrow \mathrm{L}(0.44), \mathrm{H} \rightarrow \mathrm{L}+1(-0.53)$ \\
& 534.5 & 2.320 & 0.088 & & $\mathrm{H} \rightarrow \mathrm{L}(0.54), \mathrm{H} \rightarrow \mathrm{L}+1(0.44)$ \\
\hline \multirow{3}{*}{ TPR3 } & 904.1 & 1.371 & 0.268 & & $\mathrm{H}-3 \rightarrow \mathrm{L}(0.11), \mathrm{H}-2 \rightarrow \mathrm{H} \rightarrow \mathrm{L}+2(0.10), \mathrm{H} \leftarrow \mathrm{L}(-0.11)$ \\
& 564.8 & 2.195 & 0.000 & 206.5 & $\mathrm{H} \rightarrow \mathrm{L}(0.70), \mathrm{H} \rightarrow \mathrm{L}+2(0.10), \mathrm{H} \rightarrow \mathrm{L}+1(-0.59)$ \\
\hline \multirow{3}{*}{ TPR4 } & 535.4 & 2.315 & 0.028 & & $\mathrm{H}-2 \rightarrow \mathrm{L}(0.11), \mathrm{H}-1 \rightarrow \mathrm{L}(0.38), \mathrm{H} \rightarrow \mathrm{L}+1(-0.11)$ \\
& 595.3 & 1.384 & 0.274 & & $\mathrm{H}-1 \rightarrow \mathrm{L}(0.57), \mathrm{H} \rightarrow \mathrm{L}+1(0.39)$ \\
\hline
\end{tabular}

\section{CONCLUSIONS}

In this work, DFT and TDDFT calculations were carried out to study the electronic, photophysical and charge transfer properties of four selected small molecules based on thienopyrazine-terthienyls (TPRi, i=1-4) at the B3LYP/6$31 \mathrm{G}(\mathrm{d}, \mathrm{p})$ level of theory. The effect of the substituent on the geometrical, electronic structures and further on the absorption properties is discussed. The absorption spectra were evaluated at the TD-B3LYP/6-31G(d,) level. The modification of the chemical structures of the molecules by introducing different substituent groups may control their HOMO/LUMO energy levels and band gaps. Since these are one of the most important factors determining the efficiencies of the BHJ solar cells made of these D-A molecules. The introduction of p-dimethoxyphenyle, fluorene, and carbazole groups decreases the gaps energies (from 2.27 to $2.06 \mathrm{eV}$ ) of resulting D-A molecules and gives rise to bathochromic shift of $\lambda$. The absorption maximums of the compounds are in the range 631-702 nm. This result shows a better overlap of the absorption spectrum with the solar spectrum. The calculated values of $V$ of the molecules blended with PCBM-C60 are varying from 0.75 to $1.05 \mathrm{eV}$. These values are sufficient for a possible efficient electron injection. Therefore, all the studied molecules can be used as material for building solar cells. Based on the Scharber's diagram, all TPRi exhibit similar power conversion efficiency $(P C E)$ close to $2 \%$. Moreover, the calculated data (IPs, EAs, and $\lambda$ ) reveal that the molecules upon study show not only fast but also balanced electron/ hole-transport performances. Thus, they may act as good materials with high efficiency in OLED applications.

\section{ACKNOWLEDGMENTS}

The authors are grateful to the association Marocainedes chimistes théoriciens AMCT for help on computation software. LHMH expresses their gratitude to the Universidad Autónoma del Estado de Hidalgo and to the Mexican National Council for Science and Technology (CONACYT) for financing part of this work through the Research Project Grant 257823 and to the Universidad Autónoma del Estado de Hidalgo. GSM thanks Department of Chemistry at the Universidad Andres Bello, Concepcion, Chile. RRT acknowledges to the Fondecyt project 11130007.

\section{REFERENCES}

1.- C. Li, M.Y. Liu, N.G. Pschirer, M. Baumgarten, K. Müllen, Chem. Rev. 110, 6817 (2010)

2.- $\quad$ A.P. Kulkarni, Y. Zhu, S.A. Jenekhe, Macromolecules 38, 1553 (2005).

3.- J.S. Ha, K. Kim, D.H. Choi, J. Am. Chem. Soc. 133, 10364 (2011).

4.- E.E. Havinga, W. TenHoeve, H. Wynberg, Synth. Met. 55, 299 (1993).

5.- G. Brocks, A. Tol, J. Phys. Chem. 100, 1838 (1996).

6.- Y. Zhang, S.K. Hau, H.-L. Yip, Y. Sun, O. Acton, A. K.-Y. Jen, Chem. Mater. 22, 2696 (2010).

7.- Y. Zou, A. Najari, P. Berrouard, S. Beaupre, B. Reda Aich, Y. Tao, M. Leclerc, J. Am. Chem. Soc. 132(15), 5330 (2010).

8.- Q. Zheng, B.J. Jung, J. Sun, H.E. Katz, J. Am. Chem. Soc. 132(15), 5394 (2010).
9.- J. Zhou, X. Wan, Y. Liu, F. Wang, G. Long, C. Li, Y. Chen, Macromol. Chem. Phys. 212(11), 1109 (2011).

10.- G. Saranya, P. Kolandaivel and K. Senthilkumar, Mol. Phys. 111, 3036 (2013).

11.- C. Kitamura, S. Tanaka, Y. Yamashita, Chem. Mater. 8(2), 57 (1996).

12.- R.L. Schwiderski, S.C. Rasmussen, J. Org. Chem. 78(11), 5453 (2013).

13.- E. Michael, R.L. Mulholland, S.C. Schwiderski, Rasmussen, Polym. Bull. 69, 291 (2012).

14.- R.A. Marcus, J. Chem. Phys. 24, 966 (1956).

15.- R.A. Marcus, Rev. Mod. Phys. 65, 599 (1993).

16.- Y-Z. Lu, A-M. Ren, J-K. Feng, L.L. Yan, X.Q. Ran, C.S. Chia, J. Phys. Chem. A 112, 12172 (2008).

17.- B. Priyanka, V. Anusha, K. Bhanuprakash, J. Phys. Chem. C 119(22), 12251 (2015).

18.- S.F. Nelsen, D.A. Trieber, R.F. Ismagilov, Y. Teki, J. Am. Chem. Soc. 123, (2001) 5684

19.- L. Yang, J-K. Feng, A-M. Ren. J. Mol. Struct. THEOCHEM 816, 161 (2007).

20.- S. Ardo, G. Meyer, J. Chem. Soc. Rev. 38, 115 (2009).

21.- G.M. Hasselman, D.F. Watson, J.R. Stromberg, D.F. Bocian, D. Holten, J.S. Lindsey, G.J. Meyer, J. Phys. Chem. B 110, 25430 (2006).

22.- M.C. Scharber, D. Mühlbacher, M. Koppe, P. Denk, C. Waldauf, A.J. Heeger, C. Brabec, J. Adv. Mater. 18, 789 (2006).

23.- Gaussian 09, Revision C.01, M. J. Frisch, G. W. Trucks, H. B. Schlegel, G. E. Scuseria, M. A. Robb, J. R. Cheeseman, J. A. Montgomery Jr, T. Vreven, K. N. Kudin, J. C. Burant, J. M. Millam, S. S. Iyengar, J. Tomasi, V. Barone, B. Mennucci, M. Cossi, G. Scalmani, N. Rega, G. A. Petersson, H. Nakatsuji, M. Hada, M. Ehara, K. Toyota, R. Fukuda, J. Hasegawa, M. Ishida, T. Nakajima, Y. Honda, O. Kitao, H. Nakai, M. Klene, X. Li, J. E. Knox, J. P. Hratchian, J. B. Cross, V. Bakken, C. Adamo, J. Jaramillo, R. Gomperts, R. E. Stratmann, O. Yazyev, A. J. Austin, R. Cammi, C. Pomelli, J. W. Ochterski, P. Y. Ayala, K. Morokuma, G. A. Voth, P. Salvador, J. J. Dannenberg, V. G. Zakrzewski, S. Dapprich, A. D. Daniels, M. C. Strain, O. Farkas, D. K. Malick, A. D. Rabuck, K. Raghavachari, J. B. Foresman, J. V. Ortiz, Q. Cui, A. G. Baboul, S. Clifford, J. Cioslowski, B. B. Stefanov, G. Liu, A. Liashenko, P. Piskorz, I. Komaromi, R. L. Martin, D. J. Fox, T. Keith, M. A. AlLaham, C. Y. Peng, A. Nanayakkara, M. Challacombe, P. M. W. Gill, B. Johnson, W. Chen, M. W. Wong, C. Gonzalez, J. A. Pople, Gaussian, Inc., Wallingford CT, 2004.

24.- S.H. Vosko, L. Wilk, M. Nusair, Can. J. Phys. 58(8), 1200 (1980).

25.- A.D. Becke, J. Chem. Phys. 98(7), 5648 (1993).

26.- A.D. Becke, Phys. Rev. A. 38(6), 3098 (1988).

27.- S. Miertus, J. Tomasi, J. Chem. Phys. 65, 239 (1982)

28.- S. Miertus, E. Scrocco, J. Tomasi, J. Chem. Phys. 1981, 55 (1981).

29.- J. Casado, R. Ponce-Ortiz, M.C. Ruiz Delgado, V. Hernandez, J.T. Lopez-Navarrete, J. Phys. Chem. B 109, 16616 (2005).

30.- I.F. Perepichka, D.F. Perepichka. Handbook of Thiophene-Based Materials: Applications in Organic Electronics and Photonics, 2 Volume, John Wiley \& Sons, Ltd., Chichester, UK, 2009.

31.- K. Chitoshi, T. Shoji, Y. Yoshiro, Chem. Mater. 8, 570 (1996). 
32.- F.V. Bolhuis, H. Wynberg, E.E. Havinga, E.W. Mejer, E.G. Stirling, J. Synth. Met. 30, 381 (1989).

33.- D.D. Kenning, K.A. Mitchell, T.R. Calhoun, M.R. Funfar, D.J. Sattler, S.C. Rasmussen, J. Org. Chem. 67, 9073 (2002).

34.- M.H. Petersen, O. Hagemann, K.T. Nielsen, M. Jorgensen, F. Krebs. Sol. Energ. Mat. Sol. C. 91, 996 (2007).

35.- A. Sema-Ozen, C. Atilgan, G. Sonmez, J. Phys. Chem. C 111, 16362 (2007).

36.- M.C.R. Delgado, V. Hernandez, J.T.L. Navarrete, S. Tanaka, Y. Yamashita, J. Phys. Chem. B 108, 2516 (2004).

37.- L. Zhang, Q. Zhang, H. Ren, H. Yan, J. Zhang, H. Zhang, J. Gu, Sol. Energ. Mat. Sol. C. 92, 581 (2008).

38.- Y. Wang, Q. Peng, Z. Li, P. He, B. Li, J. Mol. Model 18, 4291 (2012).

39.- J.R. Reynolds, A.D. Child, J.P. Ruiz, S.Y. Hong, D.S. Marynick, Macromolecules 26, 2095 (1993).

40.- M.A. De Oliveira Helio, A. Duarte Pernaut, J.M. Wagner, B. De Almeida, J. Phys. Chem. A 104, 8256 (2000).

41.- C.J. Brabec, S. Gowrisanker, J.J.M. Halls, D. Laird, S. Jia, S.P. Williams, Adv Mater. 22, 3839 (2010).

42.- C.J. Brabec, N.S. Sariciftci, J.C. Hummelen, Adv. Funct. Mater. 11, 15
(2001).

43.- G. Dennler, M.C. Scharber, C. Brabec, Adv. Mater. 21, 132 (2009).

44.- J.W. Chen, Y. Cao, Acc. Chem. Res. 42, 1709 (2009).

45.- Zaumseil J., Sirringhaus H, Chem Rev. 107, 1296 (2007).

46.- R. Schmidt, J.H. Oh, Y.-S. Sun, M. Deppisch, A.-M. Krause, K. Radacki, H. Braunschweig, M. Konemann, P. Erk, Z. Bao, F. Wurthner, J. Am. Chem. Soc. 131, 6215 (2009).

47.- C.R. Newman, C.D. Frisbie, D.A. Da Silva Filho, J.-L. Bredas, P.C. Ewbank, K.R. Mann, Chem. Mater. 16, 4436 (2004).

48.- G. Saranya, P. Kolandaivel, K. Senthilkumar, Mol. Phys. 111(20), 3036 (2013).

49.- E. Bundgaard, F.C. Krebs. Sol. Energ. Mat. Sol. C. 91, 954 (2007)

50.- M. Helgesen, S.A. Gevorgyan, C.K. Frederik, Chem. Mater. 21, 4669 (2009).

51.- J.P. Nietfeld, R.L. Schwiderski, T.P. Gonnella, S.C. Rasmussen, J. Org Chem. 76, 6383 (2011)

52.- S.C. Rasmussen, J.S. Daniel, K.A. Mitchell, J. Maxwell, J. Lumin. 109, 111 (2004).

53.- E. Wang, M. Wang, L. Wang, C. Duan, J. Zhang, W. Cai, C. He, H. Wu, Y. Cao, Macromol. 42, 4410 (2009). 